\title{
Self-directed treatment for lower limb wounds in persons with diabetes: a short report
}

\author{
This article was published in the following Dove Press journal: \\ Patient Preference and Adherence \\ 2 September 2014 \\ Number of times this article has been viewed
}

\section{Patrick Harnarayan \\ Shamir O Cawich \\ Shariful Islam \\ Shivaa Ramsewak \\ Vijay Naraynsingh}

Department of Clinical Surgical Sciences, University of the West

Indies, St Augustine Campus,

Trinidad and Tobago
Correspondence: Shamir O Cawich Department of Clinical Surgical Sciences, University of the West Indies, St Augustine Campus,

Trinidad and Tobago

Tel +l 8687989627

Email socawich@hotmail.com
Aim: There has been little focus on self-directed treatment for lower limb wounds, although it a common practice among persons with diabetes across the Caribbean. We sought to document this practice in a Caribbean nation.

Methods: We prospectively interviewed all consecutive patients with diabetes who were admitted with lower limb wounds at the San Fernando General Hospital in Trinidad and Tobago over a period of 18 months. A questionnaire was used to collect data on patient demographics, use of self-directed treatment, and details of these treatments.

Results: Of 839 persons with diabetes who were admitted with infected lower limb wounds, $344(41 \%)$ admitted to self-directed treatment before seeking medical attention. These patients were predominantly male $(59.9 \%)$ at a mean age of $56.4 \pm 12.4$ years. The practice was most common in persons of Afro-Caribbean descent (45.9\%) and those with type 2 diabetes (93.9\%). In this group, 255 (74.4\%) patients were previously admitted to hospital for lower limb infections. And of those, 32 (12.6\%) had a prior amputation and $108(42.4 \%)$ had at least one operative debridement specifically for foot infections.

Conclusion: Caribbean cultural practices may be an important contributor to negative outcomes when treating lower limb wounds in persons with diabetes. Despite being acutely aware of the potentially devastating consequences of inadequate treatment, $41 \%$ of our patients with diabetes still opted to use self-directed treatment for lower limb wounds. This deserves further study in order to give a more tailored approach in care delivery.

Keywords: diabetes, foot infection, alternative, home, remedy, amputation

\section{Background}

The treatment of infected lower limb wounds in persons with diabetes required an annual national expenditure of US\$85 million ( $0.4 \%$ of the gross domestic product) in Trinidad and Tobago between June 2012 and June 2013. ${ }^{1}$ This has generated significant interest from policy makers and researchers across the region, with a heavy focus on the epidemiology, ${ }^{2-6}$ prevention, ${ }^{7-9}$ and therapeutic protocols ${ }^{10-13}$ used to treat infected wounds on the lower limbs of persons with diabetes.

However, there has been little focus on these patients' practices of self-directed treatment despite it being a common practice across the Caribbean. This study sought to document the practice of self-directed treatment of infected lower limb wounds in persons with diabetes in a small Caribbean country.

\section{Methods}

This study was carried out at the San Fernando General Hospital in Trinidad and Tobago. This is one of three tertiary referral hospitals on the island and serves a catchment of approximately 400,000 persons. In order to ensure that there is no financial 
barrier to health care access, the Government of Trinidad and Tobago prohibits user fees from being generated at this facility for all legal residents.

Patients who present to the San Fernando General Hospital with infected lower limb wounds are evaluated in the casualty department. These patients are admitted to hospital when there are systemic signs of infection, evidence of deep tissue infection, leukocytosis, metabolic derangements and/ or ischemia present.

Once patients are admitted to hospital, the attending surgeon is responsible for care. They routinely evaluate the patients for limb ischemia, neuropathy, deep-seated collections/abscesses, ulcers, and generalized sepsis. The PEDIS (Perfusion, Extent/size, Depth/tissue loss, Infection, and Sensation) classification system developed by the International Working Group on the Diabetic Foot ${ }^{14}$ was used to classify diabetic foot ulcers at this facility. This is a standardized grading system that assesses foot ulcers based on the presence of five parameters: limb ischemia, wound size, wound depth, infection, and neuropathy.

Permission to interview patients was granted by the University of the West Indies' Ethics Committee. Admission registers were used to identify all consecutive patients with diabetes admitted to the San Fernando General Hospital with a diagnosis of infected lower limb wounds over 18 months from January 1, 2012 to June 30, 2013. All consecutive patients admitted were interviewed within 24 hours of admission. Patients were excluded if they were younger than 16 years of age, declined to participate, or did not admit to the use of self-directed therapy. A questionnaire was used to collect data on patient demographics, social circumstances, lifestyle habits, medical therapy, self-directed treatment, and details of these methods.

The data were analyzed using the Statistical Package for the Social Sciences (SPSS) version 14 (SPSS Inc., Chicago, IL, USA). This statistical software is widely used for data management and statistical analysis on data sets. Descriptive analyses (cross tabulations, frequencies, and descriptive ratio statistics) were generated using the populated data spreadsheets.

\section{Results}

There were 839 patients with diabetes admitted with infected lower limb wounds over the study period and 344 (41\%) admitted for deliberate use of self-directed treatments before seeking professional medical care. These patients were predominantly male $(59.9 \%$ versus $40.1 \%)$ at an average age of 56.4 years (standard deviation $[\mathrm{SD}] \pm 12.4$; range $24-93$ ).
Table I Baseline characteristics of 344 patients who used selfdirected treatment instead of presenting for medical advice and treatment

\begin{tabular}{ll}
\hline Characteristic & N (\%) \\
\hline Duration of diabetes (mean \pm SD) & $12.9 \pm 7.9$ years \\
Current smokers & $98(28.5 \%)$ \\
Regular alcohol use & $120(34.9 \%)$ \\
Male sex & $206(59.9 \%)$ \\
Female sex & $138(40.1 \%)$ \\
Afro-Caribbean descent & $158(45.9 \%)$ \\
East Indian descent & $141(41.0 \%)$ \\
Mixed descent & $41(11.9 \%)$ \\
Chinese descent & $4(1.2 \%)$ \\
Prior counseling on diabetes management & $344(100 \%)$ \\
Prior counseling on foot complications & $344(100 \%)$ \\
\hline
\end{tabular}

Abbreviation: SD, standard deviation.

The majority used oral hypoglycemics $(177,51.5 \%)$ to control their diabetes. Others used combinations of insulin and oral hypoglycemics $(103,29.9 \%)$, used insulin only (46, $13.4 \%)$, or used only self-directed treatment $18(5.2 \%)$ for glycemic control.

The baseline characteristics of the patients who used selfdirected treatment are outlined in Table 1 . The practice was most common in persons of Afro-Caribbean descent (45.9\%) and persons with type 2 (formerly known as non-insulin dependent or adult onset) diabetes (93.9\%). They had lived with diabetes for a mean duration of 12.9 years $(\mathrm{SD} \pm 7.9$; median 12; mode 10) and all patients reported that they were previously counseled on the importance of glycemic control, foot care, and early presentation of lower limb wounds.

Nevertheless, the patients had poor glycemic control in the weeks prior to hospital presentation as evidenced by mean glycosylated hemoglobin $\left(\mathrm{HbA}_{1 \mathrm{c}}\right)$ levels of $7.82 \%$ ( $\mathrm{SD} \pm 1.56$; median 7.9; mode 8.78). Additionally, 255 (74.4\%) of these patients had previous hospital admissions for diabetic foot complications. And of those, $32(12.6 \%)$ had a prior amputation and $108(42.4 \%)$ had at least one operative debridement specifically for foot infections.

The patients attempted trials of self-directed treatment that lasted for a mean duration of 8.8 days ( $\mathrm{SD} \pm 5.4$; range 1-60). Multiple agents were used as outlined in Table 2. Topical agents were more commonly employed than oral treatments $(85.1 \%$ versus $9.6 \%$, respectively). Unspecified oral therapies were used in 33 cases; 9 (2.6\%) patients had "pills" purchased from informal vendors, 12 (3.5\%) had "left-over pills" from uncompleted antibiotic courses previously prescribed for other persons to treat other diseases, and $12(3.5 \%)$ had unspecified herbal concoctions specifically to treat lower limb infections. 
Table 2 Self-directed treatment for diabetic foot infections in Trinidad and Tobago

\begin{tabular}{|c|c|c|c|c|}
\hline Agent & $n=344$ & Method of use & Dose & Frequency \\
\hline Oral Therapies & 33 & & & \\
\hline $\begin{array}{l}\text { Unspecified herbal } \\
\text { concoctions }\end{array}$ & $12(3.5 \%)$ & Premixed herbal mixtures & One cup & Twice daily \\
\hline “Left-over pills" & $12(3.5 \%)$ & $\begin{array}{l}\text { "Left-over pills" from uncompleted antibiotic courses } \\
\text { that were previously prescribed for other persons } \\
\text { to treat other diseases - patients usually followed } \\
\text { directions as printed on the dispensed container }\end{array}$ & Variable & Variable \\
\hline $\begin{array}{l}\text { "Pills" purchased from } \\
\text { informal vendors }\end{array}$ & $9(2.6 \%)$ & Red and white "pills" as provided by informal vendors & One pill & Twice daily \\
\hline Topical Therapies & 311 & & & \\
\hline $\begin{array}{l}\text { Soft candle } \\
\text { (paraffin wax) }\end{array}$ & $66(19.2 \%)$ & $\begin{array}{l}\text { Melt candle with open flame and allow hot wax to drop } \\
\text { onto the wound, then cover with a brown paper bag }\end{array}$ & Unspecified & Variable \\
\hline Honey & $56(16.3 \%)$ & Solution applied directly onto the wound & Generous & Variable \\
\hline $\begin{array}{l}\text { Wonder of world } \\
\text { (Kalanchoe Pinnata) }\end{array}$ & $40(11.6 \%)$ & $\begin{array}{l}\text { Heat leaves and apply leaf as a plaster onto the wound } \\
\text { ( } \pm \text { paraffin wax) }\end{array}$ & Unspecified & Once daily \\
\hline Ichthammol ointment & $36(10.5 \%)$ & Apply paste directly onto wound and leave uncovered & Unspecified & Once daily \\
\hline Aloe vera & $36(10.5 \%)$ & $\begin{array}{l}\text { Slice aloe leaves lengthwise and apply cut surface } \\
\text { directly onto the wound. }\end{array}$ & Unspecified & Variable \\
\hline $\begin{array}{l}\text { Heated cooking oil, } \\
\text { grease or vaseline }\end{array}$ & $36(10.5 \%)$ & $\begin{array}{l}\text { Heat over open fire until melted and then poured } \\
\text { directly onto wound }\end{array}$ & Unspecified & Variable \\
\hline lodex ointment & $23(6.7 \%)$ & Apply paste directly onto wound & Generous & Variable \\
\hline Epsom salt soak & $9(2.6 \%)$ & One cup of Epsom salts dissolved in hot water & I5 minute soak & Twice daily \\
\hline Methylated spirits & $5(1.5 \%)$ & Solution poured onto wound and then covered & Generous & Thrice daily \\
\hline Hydrogen peroxide & $2(0.6 \%)$ & $\begin{array}{l}\text { Solution poured onto cotton swabs and then applied } \\
\text { directly onto wound }\end{array}$ & Generous & Variable \\
\hline Green papaya & $2(0.6 \%)$ & Minced green papaya paste applied directly onto wound & Generous & Variable \\
\hline
\end{tabular}

\section{Discussion}

Approximately $15 \%$ of the general adult population in Trinidad and Tobago has diabetes mellitus. ${ }^{1}$ These persons have $0.75 \%$ annual risk to develop lower limb infections. ${ }^{1}$ When they do, they have a high age-standardized amputation rate, approximately 54 per 100,000 between the ages of 30 and 60 years. ${ }^{12}$

Although much research has been done on diabetic foot complications in the Caribbean, ${ }^{1-13}$ these data are incomplete without the understanding of the existing cultural practices in persons with diabetes, who are prone to developing lower limb infections. This paper demonstrates that up to $41 \%$ of persons initially opt for self-directed treatments and delay seeking medical opinions for a mean duration of $8.8 \pm 5.4$ days. This is a disappointing result because delayed medical intervention has been previously established as an independent predictor of amputation risks. ${ }^{15,16}$

Hennis et al ${ }^{13}$ studied a population of Afro-Caribbean patients with diabetic foot infections in Barbados where the amputation rates were among the highest in the world. ${ }^{17,18}$ They concluded that the high amputation risk was due to the use of inadequate footwear, poorly controlled diabetes, undiagnosed peripheral neuropathy, and untreated peripheral arterial occlusive disease. ${ }^{15}$ Teelucksingh et $\mathrm{al}^{9}$ also identified the use of traditional footwear as a contributor to poor therapeutic outcomes in a Trinidadian population. However, we believe that the practice of self-directed treatment may also be a significant contributor to the poor outcomes. There has been little focus on this practice in the Caribbean, but our anecdotal experience is that the patients' strong cultural belief in self-directed treatments often supersedes their perceptions of conventional medical treatments.

These outcomes were particularly alarming considering that $74 \%$ of the patients were previously hospitalized for diabetic foot complications. We expected that they would be acutely aware of the consequences of this disease, especially since $13 \%$ of them were amputees and $42 \%$ had operative debridement to avert the threat of limb loss. Further, patients had limited awareness of the disease despite the fact they were able to recall being counseled about the importance of glycemic control and foot care at some point before disease presentation. Most patients were counseled at dedicated diabetes clinics that are scattered throughout the communities in Trinidad and Tobago. Additionally, 69\% of persons were poorly controlled in the 12 -week period preceding 
admission as evidenced by $\mathrm{HbA}_{1 \mathrm{c}}$ levels greater than $7 \%$. This shows that despite all the work dedicated to diabetic foot complications, ${ }^{1-18}$ we have still not properly addressed secondary prevention to this captive audience.

Finally, a disturbing trend uncovered was the use of unknown "pills" by $6.4 \%$ of patients, half of which were readily available from unregulated "informal vendors". This deserves closer attention by the national regulatory bodies.

\section{Study limitations}

There were several limitations to this study. Firstly, this was a cohort study so we were not able to compare outcomes with conventional managements to determine whether this method of treatment is beneficial or not. This may be the focus for further work, possibly with a more robust blindedrandomized methodology.

Secondly, an investigator interviewed diabetic patients who developed lower limb infections to collect data for this study, relying wholly on the information supplied by the patients. We acknowledge that this may have introduced some degree of bias because the patients may not have divulged accurate information for the fear that this may alter the care they receive.

Finally, it is evident that these patients made a conscious effort to choose self-directed treatment over conventional medical advice and treatment. Therefore, they may have believed that the medical personnel do not understand these forms of traditional treatments. Hence, they may have not been cooperative with the process of data collection.

\section{Conclusion}

Caribbean cultural practices may be an important contributor to poor outcomes from diabetic foot complications. This is an area of research that deserves more attention in order to provide a tailored approach in care delivery.

Despite being acutely aware of the potentially devastating consequences of inadequate treatment, $41 \%$ of our patients still opted to use self-directed treatments for up to 8.8 days

We must reinforce public health education strategies so that patients promptly seek medical care. Policy makers should also focus on removing any barriers including cultural resistance to accessing health care.

\section{Disclosure}

There are no existing financial interests or other commitments that may represent potential conflicts of interest for any of the authors. No funding was received for this work.

\section{References}

1. Cawich SO, Islam S, Hariharan S, et al. The Economic Impact of Hospitalization for Diabetic Foot infections in a Caribbean Nation. Perm J. 2014;18(1):101-104

2. Samuels TA, Hospedales CJ. From Port-of-Spain Summit to United Nations High Level Meeting CARICOM and the Global Non-communicable Disease Agenda. West Ind Med J. 2011;60(4): 387-391.

3. Boyne MS. Diabetes in the Caribbean: Trouble in paradise. Insulin. 2009;4(2):94-105.

4. Ferguson RS, Tulloch-Reid MK, Wilks RJ. Epidemiology of Diabetes Mellitus in Jamaica and the Caribbean: A Historical Review. West Ind Med J. 2010;59(3):259-264.

5. Hennis A, Wu SY, Nemesure B, Li X, Leske MC. Diabetes in a Caribbean Population: Epidemiological Profile and Implications. Int $J$ Epidemiol. 2002;31:234-239.

6. Islam S, Harnarayan P, Cawich SO, et al. Epidemiology of Diabetic Foot Infections in an Eastern Caribbean population: A Prospective Study. Perm J. 2013;17(2):37-40.

7. Solomon S, Affan AM, Gopie P, et al. Taking the next step in 2005, the year of the diabetic foot. Primary Care Diabet. 2008;2:175-180.

8. Islam S, Harnarayan P, Cawich SO, et al. Secondary Prevention of Diabetic Foot Infections in a Caribbean Nation: A Call for Improved Patient Education. Int J Low Extrem Wounds. 2013;12(3):232-236.

9. Teelucksingh S, Ramdass MJ, Charan A, Mungalsingh C, Seemungal T, Naraynsingh V. The Slipping Slipper Sign: A Marker of Severe Peripheral Diabetic Neuropathy and Foot Sepsis. Postgrad Med. 2009; 85:288-291.

10. Teelucksingh $\mathrm{S}$, Naraynsingh $\mathrm{V}$. Injury to diabetic feet by thumb tacks. Lancet. 1997;350:7.

11. Islam S, Cawich SO, Budhooram S, et al. Microbial profile of diabetic foot infections in Trinidad and Tobago. Prim Care Diabetes. 2013;7(4): 303-308.

12. Gulliford MC, Ariyanayagam-Baksh SM, Bickram L, Picou D, Mahabir D. Counting the cost of diabetic hospital admissions from a multiethnic population in Trinidad. Diabet Med. 1995;12(12):1077-1085.

13. Hennis AJ, Frazer HS, Jonnalagadda R, Fuler J, Chaturvedi N. Explanations for the high risk of diabetes related amputation in a Caribbean population of black African descent and potential for prevention. Diabet Care. 2004;27(11):2636-2641.

14. Valk GD, Kriegsman DM, Assendelft WJ. Patient education for preventing diabetic foot ulceration: a systematic review. Endocrinol Metab Clin North Am. 2002;31:633-658.

15. Hennis A, Wu SY, Nemesure B, Li X, Leske MC. Diabetes in a Caribbean population: epidemiological profile and implications. Int J Epidemiol. 2002;31:234-239.

16. Lipsky BA, Berendt AR, Cornia PB, et al. Infectious Diseases Society of America. 2012 Infectious Diseases Society of America Clinical Practice Guidelines for the Diagnosis and Treatment of Diabetic Foot Infections. Clin Infect Dis. 2012;54(12):132-173.

17. Walrond ER. The Caribbean experience with the diabetic foot management of the diabetic foot. West Ind Med J. 2001;50(S7):24-26.

18. Hambleton IR, Jonnalagadda R, Davis CR, Fraser HS, Charurvedi N, Hennis AJ. All-cause mortality after diabetes-related amputation in Barbados: a prospective case-control study. Diabetes Care. 2009;32(2): 306-307. 
Patient Preference and Adherence

Dovepress

\section{Publish your work in this journal}

Patient Preference and Adherence is an international, peer-reviewed, open access journal that focuses on the growing importance of patient preference and adherence throughout the therapeutic continuum. Patient satisfaction, acceptability, quality of life, compliance, persistence and their role in developing new therapeutic modalities and compounds to optimize

Submit your manuscript here: http://www.dovepress.com/patient-preference-and-adherence-journa clinical outcomes for existing disease states are major areas of interest for the journal. This journal has been accepted for indexing on PubMed Central. The manuscript management system is completely online and includes a very quick and fair peer-review system, which is all easy to use. Visit http://www. dovepress.com/testimonials.php to read real quotes from published authors. 